1

2

3

4

5

6

7

8

9

10

11

12

13

14

15

16

17

18

19

20

21

22

23

24

25

26

27

28

29

30

31

32

33

34

35

36

37

38

39

40

41

42

43

44

45

46

47

48

49

\title{
Climate change and the potential distribution of Xylella fastidiosa in Europe
}

\author{
Martin Godefroid ${ }^{1}{ }^{2}$, Astrid Cruaud ${ }^{1}$, Jean-Claude Streito ${ }^{1}$, Jean-Yves Rasplus ${ }^{1}$ and Jean- \\ Pierre Rossi ${ }^{*}$ \\ ${ }^{1}$ CBGP, INRA, CIRAD, IRD, Montpellier SupAgro, Univ. Montpellier Montpellier, France. \\ ${ }^{2}$ Present address: Fisheries \& Oceans Canada, Pacific Biological Station, Nanaimo, B.C \\ *corresponding author: jean-pierre.rossi@inra.fr
}

\begin{abstract}
The bacterium Xylella fastidiosa ( $\mathrm{X}$ ) is a plant endophyte native to the Americas that causes worldwide concern. $X f$ has been recently detected in several regions outside its natural range including Europe. In that context, accurate estimates of its response to climate change are required to design cost-efficient and environment-friendly control strategies. In the present study, we collected data documenting the native and invaded ranges of the three main subspecies of Xf: fastidiosa, pauca and multiplex, as well as two strains of $X f$ subsp. multiplex recently detected in southern France (ST6 and ST7). We fitted bioclimatic species distribution models (SDMs) to forecast their potential geographic range and impact in Europe under current and future climate conditions. According to model predictions, the geographical range of $X f$ as presently reported in Europe is small compared to the large extent of suitable areas. The European regions most threatened by $X f$ encompass the Mediterranean coastal areas of Spain, Greece, Italy and France, the Atlantic coastal areas of France, Portugal and Spain as well as the southwestern regions of Spain and lowlands in southern Italy. Potential distribution of the different subspecies / strains are contrasted but all are predicted to increase by 2050, which could threaten several of the most economically important wine-, olive- and fruitproducing regions of Europe, warranting the design of control strategies. Bioclimatic models also predict that the subspecies multiplex might represent a threat to most of Europe under current and future climate conditions. These results may serve as a basis for future design of a spatially informed European-scale integrated management strategy, including early detection surveys in plants and insect vectors, quarantine measures as well as agricultural practices.
\end{abstract}

Keywords Pierce's disease, species distribution models, global change, biological invasions, risk assessment

\section{Introduction}

The bacterium Xylella fastidiosa ( $\mathrm{Xf}$ ) is a plant endophyte native to the Americas, that develops in up to 300 plant species including ornamental and agricultural plants ${ }^{1}$. In its native range, $X f$ is transmitted between plants by xylem-feeding insects belonging to several families of Hemiptera (Aphrophoridae, Cercopidae, Cicadellidae, Cicadidae and Clastopteridae) ${ }^{2}$. Xf causes severe plant pathologies leading to huge economic losses ${ }^{3}$, including the Pierce's disease of grapevines PD: ${ }^{4}$, the olive quick decline 5 , the oak bacterial leaf scorch ${ }^{6}$, the phony peach disease ${ }^{7}$, the Citrus variegated chlorosis CVC: ${ }^{8}$ and the almond leaf scorch ${ }^{9}$. As $X f$ can colonize a large number of economically important plants including vine ${ }^{1}$, its biology and the mechanisms of vector transmission have been extensively studied to design management strategies ${ }^{10}$. On the basis of genetic data obtained with Multilocus Sequence Typing MLST: ${ }^{11,12}, X f$ was subdivided into six subspecies (fastidiosa, pauca, multiplex, sandyi, tashke and morus). The 
50

51

52

53

54

55

56

57

58

59

60

61

62

63

64

65

66

67

68

69

70

71

72

73

74

75

76

77

78

79

80

81

82

83

84

85

86

87

88

89

90

91

92

93

94

95

96

97

98

subspecies were further characterized by different geographic origins, distributions and host preferences in the Americas ${ }^{13-15}$. However, the status of the different subspecies is still a matter of debate ${ }^{16}$ and only two, fastidiosa and multiplex, are formally considered valid names ${ }^{1,17}$. Xf subsp. fastidiosa ${ }^{18}$ occurs in North and Central America, where it causes, among others, the harmful PD and the almond leaf scorch (ALS). Genetic analyses suggest that this subspecies originated from southern parts of Central America 19. The subspecies multiplex is widely distributed in North America (from California to western Canada and from Florida to eastern Canada), where it was detected on a wide range of host plants (e.g. oak, elm, maple, almond, sycamore, Prunus sp., etc.) as well as in South America 20,21. The subspecies pauca, which causes severe diseases in Citrus (CVC) and coffee (Coffee Leaf Scorch: ${ }^{22}$ ) in South and Central America, is thought to be native to South America ${ }^{23}$. The subspecies morus recently proposed by Nunney et al ${ }^{24}$, occurs in California and eastern USA, where it is associated to mulberry leaf scorch. $X f$ subsp. sandyi, responsible for oleander leaf scorch, is distributed in California ${ }^{12}$, while the subspecies tashke was proposed by Randall et al ${ }^{25}$ for a strain occurring on Chitalpa tashkentensis in New Mexico and Arizona. Overall, intraspecific entities of Xf display differences in host range suggesting that the radiation of $X f$ into multiple subspecies and strains is primarily associated to host specialization ${ }^{26}$.

Xylella fastidiosa is now of worldwide concern as human-mediated dispersal of contaminated plant material has allowed the bacterium to spread outside its native range. In 2013, the CoDIRO strain (subsp. pauca) was detected on olive trees in southern part of the Apulia territory (Italy). Genetic analyses suggested that it was accidentally introduced from Costa Rica or Honduras with infected ornamental coffee plants ${ }^{5}$. Since then, $X f$ subsp. pauca has spread northward and killed millions of olive trees in the Apulia territory, causing unprecedented socio-economic issues. During the period 20152017 several subspecies and strains were detected on ca 30 different host plants in Southern France (PACA region) and Corsica 27. According to this survey, the vast majority of plant samples were contaminated by two strains of $X f$ subsp. multiplex (referred here to as the French ST6 and ST7 strains). These strains are closely related to the Californian strains Dixon (ST6) and Griffin (ST7), belonging to the "almond group" of Nunney et al (2013) and were detected on numerous plant species though without evident specialization. To a lesser extent, other strains were detected in Southern France. Thus, the strain ST53 (Xf subsp. pauca) was detected on Polygala myrtifolia in Côte d'Azur (Menton) and on Quercus ilex in Corsica ${ }^{27}$. Finally, recombinants strains (ST76, ST79 or not yet fully characterized) were detected in a few plant samples. In 2016, Xf subsp. fastidiosa was detected on rosemary and oleander plants overwintering in a nursery in Germany ${ }^{28}$. In 2017, Spanish plant biosecurity agencies officially confirmed the detection of $X f$ strains belonging to the subspecies multiplex, pauca and fastidiosa on almond trees, grapevine, cherry and plums in western parts of the Iberian Peninsula and Balearic islands ${ }^{29}$. Outside Europe, the detection of $X f$ was officially confirmed in Iran on almond trees and grapevines ${ }^{30}$, in Turkey ${ }^{31}$ as well as in Taiwan on grapevines ${ }^{32}$. The severity of $X f$-induced diseases has recently dramatically increased in several areas possibly due to global warming ${ }^{33}$. Indeed, it has been demonstrated that cold winter temperatures might affect the survival of $X f$ in xylem vessels and allow plants to partly recover from $X f$-induced diseases 'cold curing phenomenon': ${ }^{34,35}$. For instance, Purcell ${ }^{34}$ showed that grapevines with symptoms of PD recovered after multiple exposures to temperatures below $-8^{\circ} \mathrm{C}$ during several hours. Further, Anas et al ${ }^{36}$ suggested that areas experiencing more than 2 to 3 days with minimal temperature below $-12.2^{\circ} \mathrm{C}$ (or alternatively 4 to 5 days below $-9.9^{\circ} \mathrm{C}$ ) should be considered at low 
99 risk for PD incidence, although these thresholds were considered too conservative by

100 Lieth et al ${ }^{37}$. There is no doubt that estimating the potential distribution of $X f$ under

101 current and future climate conditions will contribute to design environment-friendly

102 and cost-efficient management strategies ${ }^{38}$. Several studies aimed to forecast the

103 potential distribution of $X f$ in Europe ${ }^{39}$ and/or all over the world ${ }^{40}$. For instance,

104 Hoddle et al ${ }^{40}$ used the CLIMEX algorithm to forecast the worldwide potential severity

105 of PD without accounting for potential future range shifts induced by global change.

106 Bosso et al ${ }^{39}$ fitted a Maxent model to forecast the potential distribution of $X f$ subsp.

107 pauca under current and future climate conditions, and concluded that climate change

108 would not affect its future distribution of Xf. However, Bosso et al ${ }^{39}$ calibrated their

109 model using solely the presence records from the invaded range in Italy, a practice that

110 is known to increase omission errors ${ }^{41}$.

111 Here, to assist in designing efficient survey as well as appropriate management

112 strategies of $X f$ in Europe, we modeled the potential distribution of three of its

113 subspecies: fastidiosa, pauca and multiplex under current and future climate conditions.

114 For finest estimates we also modeled the potential distribution of the two strains of the

115 subsp. multiplex that seem largely distributed in Southern France (i.e. the French ST6

116 and ST7). Finally, to go one step further, we estimated the severity of the Pierce's

117 Disease (caused by $X f$ subsp. fastidiosa) in European ecosystems based on US Pierce

118 Disease intensity/occurrence maps provided by A. Purcell (available in Kamas et al ${ }^{42}$

119 and in Anas et al ${ }^{36}$ ).

120

121

122

123

124

125 We collected occurrence data for subspecies pauca and multiplex in both their native

126 and invaded ranges from the scientific literature, field surveys and public databases (Fig.

127 1). We also used data on the distribution of the strains ST6 and ST7 in France that were

128 collected in 2015-2017 and stored in the French national database managed by the

129 French Agency for Food, Environmental and Occupational Health \& Safety (ANSES) (Fig.

130 1B). For the subspecies fastidiosa, we randomly generated 400 occurrences within its

131 traditional range and assigned to each record a PD severity index (index 1: low severity;

132 index 2: moderate severity; index 3: high severity) according to PD intensity maps

133 provided by A. Purcell (available in Anas et al ${ }^{36}$ and Kamas et al ${ }^{42}$ ) (Fig. 1A). High

134 severity regions comprise Florida, south of Alabama, Texas, Louisiana and Mississippi

135 states as well as Los Angeles basin in California and coastal areas of South and North

136 Carolina (Fig. 1A). Moderate severity areas comprise north of Alabama, Georgia, Texas,

137 Louisiana and Mississippi states as well as some wine-producing regions of California

138 (Napa valley, Sonoma valley, Santa Clara valley) where severe PD outbreaks occurred

139 during the $20^{\text {th }}$ century even though it was an unusual phenomenon. Low severity

140 regions encompass most of Virginia, Oklahoma, North Texas, Kentucky etc. as well as

141 localities in Washington State ${ }^{34}$. Pierce's disease symptoms associated to the presence

142 of $X f$ were recently detected in West Virginia ${ }^{33}$, Oklahoma ${ }^{43}$ and high elevation regions

143 of Texas ${ }^{42}$. The emergence of PD in these regions may, however, have been induced by

144 the recent increase of temperatures occurring in the late 1990's and in 2000's. We

145 deliberately considered these regions as low-risk areas because climate descriptors

146 used in the present study represent average climate conditions for the 1970-2000 
147 period (see below) and do not account for temperature changes that occurred at the

148 very end of the $20^{\text {th }}$ century and the beginning of the $21^{\text {th }}$ century.

149

150

151

152

\section{Bioclimatic descriptors}

We used a set of bioclimatic descriptors hosted in the Worldclim database bio1 to bio19

153 see ${ }^{44}$. We used raster layers of 2.5-minute spatial resolution, which corresponds to about $4.5 \mathrm{~km}$ at the equator. The data come in the form of a raster map and represent the average climate conditions for the period 1970-2000. We estimated the future potential distributions of the different subspecies of $X f$ in 2050 and 2070 using the Model for Interdisciplinary Research on Climate version 5 MIROC5 ${ }^{45}$. These predictions of future temperature and precipitation rank among the most reliable according to model evaluation procedures used in AR5 of IPCC ${ }^{46}$. We used two different climatic

160

161

162

163 datasets relative to the representative concentration pathways RCP4.5 and RCP8.5, which assume moderate and extreme global warming, respectively ${ }^{47}$.

\section{Models}

165

166

The PD severity index being an ordinal categorical variable $(1<2<3)$ it was modeled

167 using a cumulative link model (CLM) also called ordinal regression models, or proportional odds models ${ }^{48}$. The CLM analyses the relationship between a set of independent variables (the climate descriptors) and an ordinal dependent variable consisting in the PD severity index. The CLM was fitted using a dataset corresponding to Pierce's disease intensity in the US (Fig. 1A). It was then used to compute the spatial distribution of the probabilities that the different classes of index occur in Europe. CLM fit and predictions were carried out using the R software version $3.3 .3^{49}$ and the $\mathrm{R}$ packages MASS 50 and ordinal 51 .

174 The potential distribution of Xf subsp. pauca, multiplex and the French ST6/ST7 were

175 estimated using species distribution modeling. Species distribution models establish

176 mathematical species-environment relationships using presence records and environmental descriptors in order to assess the potential distribution of species or map the habitat suitability ${ }^{52}$. We used two presence-only approaches namely Bioclim 53,54 and Domain ${ }^{55}$. These algorithms are climatic envelope approaches. As such, they are based on presence records and do not make any assumptions about the absence of the organism under study. We selected these approaches because they are well suited to poorly documented species for which reliable absences are unavailable ${ }^{54,56}$. In addition, we deliberately did not fit SDMs which rely on complex mathematical relationships among descriptors such as e.g. Maxent: ${ }^{57}$ as we used only a few climate descriptors (see below).

186 Both Bioclim and Domain yield an index of habitat suitability that can be categorized to form a binary map (species presence vs. absence or suitable vs. unsuitable habitat). We used the lowest presence threshold (LPT) 58 i.e. the lower value of predicted climatic suitability associated to presence records. SDM fit and predictions were carried out using the R package di smo ${ }^{59}$.

191

192

193

194

195 
196

197

198

199

200

201

202

203

204

205

206

207

208

209

210

211

212

213

214

215

216

217

218

219

220

221

222

223

224

225

226

227

228

229

230

231

232

233

234

235

236

237

238

239

240

241

242

243

244

\section{Procedure to select climate predictors}

The models were intentionally fitted using a limited number of ecologically relevant climate descriptors to avoid model over-parameterization, which is a recommended practice in the context of invasion risk assessment ${ }^{60}$.

$\underline{C L M}$. Although $X f$ geographical distribution appears to be primarily driven by minimum temperatures, the dynamics of the plant-pathogen-vector system is complex ${ }^{61}$ and rainfall may impact the severity of the disease by affecting the bacterium pathogenicity or the intensity of the vection by insects.

The CLM was fitted using a set of climate variables that represent possible significant ecological stressors (maximum temperature of warmest month (bio5), minimum temperature of coldest month (bio6), mean temperature of warmest quarter (bio10), mean temperature of coldest quarter (bio11), precipitation of wettest quarter (bio16), precipitation of driest quarter (bio17), precipitation of warmest quarter (bio18) and precipitation of coldest quarter (bio19)). We used a stepwise model selection by AIC to identify the best performing variable subset, which finally comprised (bio10: mean temperature of warmest quarter, bio11: mean temperature of coldest quarter and bio18: precipitation of warmest quarter). Because the impact of precipitations upon PD severity pattern at large spatial scales is not well documented we performed the computations using the full model (bio10, bio11 and bio18) and a model comprising only the temperature predictors (bio10 and bio11).

$\underline{S D M}$. A first step consisted into fitting and evaluating both Bioclim and Domain models using 10 different climate datasets combining maximal and minimal temperatures descriptors (bio5: maximum temperature of the warmest month; bio6: minimum temperature of the coldest month; bio10: mean temperature of the warmest quarter; bio11: mean temperature of the coldest quarter) (Table 1). We did not include descriptors of rainfall since we were interested in modeling distribution only (not severity) ${ }^{34}$. At this stage, models were fitted using only the occurrences available in the native area of each subspecies or French occurrences of the ST6 and ST7 strains (Fig. 1B, $\mathrm{C}, \mathrm{D})$. This allowed us to evaluate the transferability of each model by calculating the proportion of actual presences in the invaded range correctly predicted using the LPT 58 i.e. model sensitivity. As a second evaluation of model transferability, we calculated the area under the curve of the receiver operator curve (AUC) from a dataset encompassing occurrences available in Europe as well as 10,000 pseudo-absences randomly generated across the European territory. For a given subspecies, the climatic dataset associated to models showing poor transferability were discarded from the study. The selected climate dataset were then used to fit Bioclim and Domain models using the occurrences available in both native and invaded ranges as recommended by various authors e.g. Broennimann and Guisan ${ }^{41}$. The models were used to estimate the habitat suitability across Europe and binary maps were generated using the threshold detailed above. For each taxonomic unit we finally constructed a suitability map by averaging the predictions of models fitted with each selected set of climatic descriptors ensemble forecasting: 62,63 .

\section{Refining species distribution models' predictions}

Some points in Europe may be associated to climate conditions that are not encountered within the range of conditions characterizing the set of reference points i.e. within the 
245 native and invaded areas. In such situations, using the species distribution models to

246 predict habitat suitability in such novel habitats can be misleading ${ }^{64}$. Elith et al 64

247 introduced the multivariate environmental similarity surface (MESS) to quantify how

248 similar a point is to a reference set of points with respect to a set of predictor variables.

249 Negative values of the MESS index indicate sites where at least one variable has a value

250 lying outside the range of environments over the reference set. We computed the MESS

251 index over Europe with reference to the occurrence dataset used to fit each species

252 distribution model. We further restricted the model predictions to areas where the

253 index was positive. We used a MESS index computed with the variable bio11 (mean

254 temperature of coldest quarter) to refine the CLM predictions because the impact of

255 winter temperatures on PD dynamics is very well documented 34,35,65. MESS

256 computations were carried out using the R package dismo ${ }^{59}$. All graphical outputs were

257 produced using the R packages ggplot2 ${ }^{66}$ and cowplot ${ }^{67}$.

258

259

260

261

262

263

264

265

266

267

268

269

270

271

272

273

274

275

276

277

278

279

280

281

282

283

284

285

286

287

288

289

290

291

292

293

\section{Results}

\section{Pierce's disease severity index}

The stepwise-selected model comprised three bioclimatic descriptors: bio10: mean temperature of warmest quarter, bio11: mean temperature of coldest quarter and bio18: precipitation of warmest quarter. The variable contribution was highly significant in all cases $\left(\mathrm{p}<10^{-3}\right)$ and the coefficients were -19.4 (bio10), 77.6 (bio11) and 3.5 (bio18). The resulting model was used to compute the values of the PD severity index across North America and Europe using climatic dataset corresponding to the period 1970-2000. In North America the MESS index revealed that areas north of 35 decimal degrees latitude were associated to strongly negative index (Fig. S1). In Europe, low index values were observed in north-eastern areas as well as in the Alps and the Pyrenees (Fig. S2). These areas were discarded from further interpretation and have been subsequently depicted in grey in the maps shown in Fig. 2. The Figs 2A and S3 show the model predictions for the three levels of severity in Europe and North America for the period 1970-2000 respectively.

The CLM predicted a risk of moderate to highly severe PD in multiple lowlands and coastal areas of the Mediterranean regions (Spain, Italy, Balearic islands and North Africa) as well as along the Atlantic coasts of France, Northern Spain and Portugal (Fig. 2A). A low to moderate severity of PD was also predicted in the Atlantic costs of France, lowlands of northern Italy, and central Spain. High severity was predicted in Sicilia (Italy), and long both the Atlantic and Mediterranean coasts of Spain.

Using the model to estimate the PD severity index according to different climate change scenarios led to the maps displayed in Fig. 2B and 2C for 2050 and Fig. S4 B and C for 2070. In each case, the MESS index was recomputed on the basis of the present and future climate conditions. Estimations for 2050 indicate an increased PD severity in south Italy, Corsica and Sardinia either with the concentration pathways RCP4.5 or the RCP8.5 (Fig. 2B, and 2C). The estimates for 2070 are pretty much similar (Fig. S4).

The CLM fitted with only bio10 and bio11 led to the results showed in Fig. S5 and S6. The main differences are that the Atlantic coasts of France, Ireland and west England are associated to severity index of 1 whereas the model including bio18 predicted a severity of 2 (Fig. S5). A similar pattern is observed for the predictions in 2070 (Figs S4 and S6). 
294

295

296

297

298

299

300

301

302

303

304

305

306

307

308

309

310

311

312

313

314

315

316

317

318

319

320

321

322

323

324

325

326

327

328

329

330

331

332

333

334

335

336

337

338

339

340

341

342

\section{Potential distribution of Xf subspecies pauca and multiplex}

Both Bioclim and Domain fitted using climate datasets \#1, \#4 and \#7 yielded high transferability measures (AUC superior to 0.85 and sensitivity $=1$ ) in the case of the subsp. pauca (Table 1). These datasets were therefore retained for further analyses. For the subsp. multiplex we selected 3 climate datasets (\#2, \#6 and \#9) associated to AUC values $>0.85$ and a sensibility of 0.999 (Table 1 ).

Regarding the subspecies pauca, the models showed that climatically suitable environments in Europe only correspond to small well-delimited areas in South Portugal and Spain, Balearic Islands, Sicilia and North Africa (Fig. 3A). There was a marked agreement between the models that all indicated very favorable environment in these areas (Fig. 3D). It is worth noting that the areas associated to negative MESS index values are very large (shaded areas in maps; i.e. areas experiencing climate conditions absent from the dataset used to calibrate the model and for which no prediction was made). This conveys the fact the subsp. pauca originates from South America (Fig. 1D) and is associated to tropical environments. Suitable environments in Europe are restricted to warmest environments around the Mediterranean Sea. The models predict changes in the location of suitable areas in Europe by 2050 (Fig. 3B-F). Areas at risk would include northern coast of Spain, south France and Tyrrhenian coast of Italy. There is no marked differences according to the scenario examined (Fig. 3) and a similar pattern is expected in 2070 (Fig. S7) except for Italy where climate conditions may become unfavorable according to scenario 8.5 (Fig S7F).

The situation is different for the subspecies multiplex which is natively distributed across North America (Fig. 1C) and for which the models depicted suitable conditions in most of Europe except high-elevation areas and cold northern regions (Fig. 4). The expected impacts of climate change are limited and mostly concern South Spain where the conditions are expected to become unfavorable by 2050 and North part of Europe that are predicted to become more favorable by 2050 (Fig. 4 B to F) and 2070 (Fig. S8). The potential distribution of the French strains ST6 and ST7 is localized to Mediterranean areas (Corsica, Sardinia, Sicilia and coastal areas of Italy and France) (Fig. 5A, D). Suitable conditions are also present in the Atlantic coasts of Portugal and in South West France. A shift in distribution is expected to occur by 2050 (Fig. 5B to F and Fig. S9). Favorable conditions are expected to extend northward while areas currently suitable such as South Western France are expected to become unfavorable. All models indicate that the Spanish Atlantic coast (Galicia, Asturias, Cantabria and Basque country) is expected to become climatically suitable by 2050 .

\section{Discussion}

\section{Geographical distribution and possible impacts in Europe}

In a rapidly changing world, the design of pest control strategies (e.g. early detection surveys and planning of phytosanitary measures) should ideally rely on accurate estimates of the potential distribution and/or impact of pest species as well as their responses to climate change ${ }^{38}$. In the present study, bioclimatic models predicted that a large part of the Mediterranean lowlands and Atlantic coastal areas are seriously threatened by $X f$ subsp. fastidiosa, multiplex and pauca. A low to moderate impact is also expected in northern and eastern regions of Europe (North-eastern France, Belgium, the Netherlands, Germany, Scandinavia, the Baltic region, Poland, Austria, Switzerland, etc.) 
343 that experience lower minimal temperature in winter but may nevertheless presumably

344 host $X f$ subsp. multiplex.

345 Models display good evaluation measures and predict moderate to high climatic

346 suitability in all European areas where symptomatic plants are currently infected by the

347 subspecies fastidiosa, pauca or multiplex (e.g. Balearic Islands, lowlands of Corsica

348 island, south-eastern France and the Apulia region). This suggests that risk maps

349 provided in the present study are reliable for the design of surveys, including 'spy

350 insects' survey ${ }^{68,69}$. They may also be helpful to anticipate the spread of the different

351 subspecies and provide guidance on which areas should be targeted for an analysis of

352 local communities of potential vectors and host plants to design management strategies

353 and research projects.

354 Our results show that the subspecies/strains of Xf studied here might significantly 355 expand in the near future, irrespective of climate change. For example, the ST6 and ST7

356 strains (subsp. multiplex) present in Corsica and southern France have a large potential

357 for expansion, whose dynamics actually depends more on plant exchanges and disease

358 management than on climate suitability per se. The subspecies multiplex is associated to

359 economically important plants such as almonds and olives ${ }^{26}$ but may also colonize

360 multiple ornamental plants. Its present potential distribution in Europe extends far

361 beyond areas where the subspecies has been reported and comprises Portugal, Italy,

362 and both South and South-western France suggesting possible important economical

363 losses.

364 The subspecies fastidiosa, which has been currently reported from a limited number of 365 localities, could encounter favorable climate conditions in various areas of Europe. The 366 model estimation of areas with a risk of PD highlights strategic wine-growing areas in 367 different countries. Notably, the present estimates of the potential impact of the subsp. 368 fastidiosa are consistent with the risk maps provided by Hoddle et $\mathrm{al}^{40}$ and A. Purcell 369 (available in Anas et al ${ }^{36}$ ). The case of subsp. pauca is somewhat different. Most of the 370 European occurrences are known from southern Italy and the Balearic Islands and the 371 potential distribution of this subspecies appears to be limited. This is not surprising 372 given that $X f$ subsp. pauca is native from South America and occupies a climatic niche 373 that mostly corresponds to areas located around the Mediterranean basin. Nevertheless, 374 southern Spain, Portugal, Sicilia and North Africa that are areas where growing olive 375 trees is multisecular offer suitable conditions, which potentially implies huge socio376 economic impacts. One factor that proved to be critical for some diseases is the 377 distribution/availability of vectors and hosts. Here, none of these factors is limiting since $378 X f$ is capable of colonizing a vast array of plants present in Europe and Philaenus 379 spumarius, the only European vector identified so far 70,71 , occurs across the whole 380 continent 69.

381 Because we used the MESS index to discard regions experiencing climate conditions 382 absent from the dataset used to calibrate the model, our estimations of potential 383 distributions are conservative. The CLM showed a positive effect of higher temperatures 384 during the coldest quarter (variable bio11 associated to a positive coefficient) on the 385 severity index which may indicate to a lower "cold curing" effect 34,65. Absence of 386 estimation of the potential distribution of $X f$ (all subspecies) or of the PD severity index 387 (Xf subsp. fastidiosa) (i.e. shaded areas of the maps) does not mean that the bacterium is 388 unable to develop but rather that evaluating the risk is difficult. For example, the 389 potential impact of $X f$ in areas experiencing extremely high temperatures in summer 390 (e.g. southern and central Spain) remains largely uncertain as the impact of extreme 391 heat on $X f$ and on the behavior of insect vectors is still poorly known ${ }^{61}$. We report a 
392 negative coefficient for the variable bio10 (mean temperature of the warmest quarter)

393 suggesting that PD severity would be negatively related to high temperatures during

394 summer. Although warm spring and summer temperatures enhance multiplication of $X f$

395 in plants, it has been showed that $X f$ populations decrease in grapevines exposed to

396 temperatures above $37^{\circ} \mathrm{C} 35$. As southern and central Spain frequently experience

397 temperatures above $40^{\circ} \mathrm{C}$ in summer, further field and laboratory experiments are

398 required to improve our estimation of the potential impact of $X f$ in these regions.

399 Another point requiring clarification is the effect of precipitation during the warmest

400 quarter that appears to be significant in the CLM. Precipitation may have direct impacts

401 on the dynamics of the relationship between $X f$ and its host as well as indirect effects

402 through the relationships with the insect vectors.

403

404

405

406

407

408

\section{Climate change and possible range shifts}

Our results clearly indicate that climate change may strongly impact the distribution of $X f$ in Europe. Indeed, as "cold curing" appears to be the main mechanism explaining the lower impact of $X f$ in colder regions, an increase of winter temperatures should make these regions more suitable for $X f$ in the next decades $34,35,65$. We report possible changes in the potential distribution of the subspecies multiplex with a northward expansion by 2070. The potential distribution of the French strains ST6 and ST7 is even more impacted with a gradual shift of suitable areas from Southern France, Italy and Portugal towards Northern France, Belgium, Netherlands and South England. The suitable areas for $X f$ subsp. pauca are expected to slightly extend to the Mediterranean coastal areas of Spain and France. The expected impact of climate change on the severity index of the PD is less marked and mostly correspond to an increased PD severity in south Italy, Corsica and Sardinia.

417

418

419 Overall, these results obtained on the different subspecies clearly indicate that climate change will alter areas at risk for invasion by $X f$ in Europe. Given that both the concentration pathways RCP4.5 and RCP8.5 led to concordant predictions, it appears sound to expect such changes even if the global warming is kept to a moderate level. SDMs showed that the subspecies multiplex displays a wider temperature tolerance and could threaten most of the European continent now and in the future. This is not surprising as this subspecies infects elms in regions of Canada characterized by low winter temperatures ${ }^{72}$. This broad tolerance to cold is not known for other subspecies and it is still unclear whether realized niche divergence among subspecies reflects inherent differences in thermal tolerances or rather host-pathogen interactions as it was observed for Ralstonia solanacearum ${ }^{73}$. More investigations would help a better understanding of the effect of temperatures on the different strains of $X f$. It is noteworthy that both present and future distributions show several areas of potential co-occurrence. This may have important implications as it may increase the risk of intersubspecific homologous recombination (IHR).

435

436

437

438

439

\section{Limits and opportunities for risk assessment}

Maps of habitat suitability and their declination with regards to future climate conditions should be guardedly interpreted as they are derived from correlative tools that depict the realized niche of species i.e. a subset of the fundamental environmental tolerances constrained by biotic interactions and dispersal limits ${ }^{74}$. In addition, we 
441 the subspecies pauca and multiplex, and of the French strains ST6 and ST7 under future 442 climate conditions. Indeed, time-periods associated to occurrences and climate 443 descriptors dataset do not perfectly overlap. The models were fitted with climate 444 descriptors that represent average climate conditions for the 1970-2000 period, while 445 most presence records were collected after 2000 in a period characterized by milder 446 winter temperatures. Moreover, as we deliberately fitted simple climate-envelope 447 approaches such as Bioclim and Domain based on few climate descriptors to avoid 448 model over-parameterization and/or extrapolation and enhance model transferability, 449 we cannot exclude that bioclimatic models presented in the study do not capture the 450 entire range of environmental tolerances and do not depict the complexity of the 451 climatic niche of $X f$ as well as potential interactions between climate descriptors. Better 452 models hence better risk assessment could be obtained if the amount of occurrence data 453 could be increased. True absences i.e. locations where the environmental conditions are 454 unsuitable for $X f$ to survive, would be particularly precious because they would allow 455 456 using powerful approaches such as the generalized linear model ${ }^{52}$. Finally, the possible adaptation of the subspecies of $X f$ to environmental constraints met in European ecosystems is another important and unknown factor of uncertainties. For example, the potential of recombinant strains to adapt should be addressed in the near future.

Finally, it is worth noting that bioclimatic models predict climatic suitability of a geographic region rather than a proper risk of $X f$-induced disease incidence. To predict the proper severity of $X f$-induced diseases in a given locality, statistical models should account for many additional factors playing a role in $X f$ epidemiology, including e.g. microclimate conditions, inter-annual climate variability, landscape structure and the spatio-temporal structure of the community of potential vectors. Although recent entomological studies identified the meadow spittlebug $P$. spumarius as the main vector of $X f$ in Italy ${ }^{70,71}$, a better knowledge of all European vectors capable of transmitting $X f$ from plant to plant as well as their ecological characteristics (geographic range, efficiency in $X f$ transmission, demography, overwintering stage, etc.) is needed ${ }^{75}$. In this context, our estimates could allow to design cost-efficient vector surveys, with priority given to geographic regions predicted as highly climatically suitable for $X f$. The study by Cruaud et al ${ }^{69}$ provides a good insight into how species distribution modeling and DNA sequencing approaches may be combined for an accurate monitoring of the range of $X f$ and its vectors in Europe. We believe that bioclimatic models are promising tools to help designing research experiments, control strategies as well as political decisions at the European scale.

\section{Conclusions/highlights}

Species distribution models all indicate that the geographical range of $X f$ as presently reported in Europe is small compared to the large extent of suitable areas. This is true for all studied subspecies of $X f$ although the subspecies pauca appears to have a smaller potential range possibly because of its Neotropical origin. Although caution is needed in interpreting spatial projections because uncertainties in future climate conditions themselves and because uncertainties associated to the predictions of the species distribution models are difficult to assess, we showed that climate change will probably affect the future distribution of the bacterium by 2050 and then 2070 . Last but not least, $X f$ has a certain potential to adapt for the specific climate and biotic interactions (hosts, vectors) present in Europe. This potential is unknown but could nevertheless lead to marked divergence between its future geographical distribution and the picture we have 
490 of it today. However, our current knowledge allows proposing different research 491 avenues to better understand and anticipate the possible expansion of $X f$ in Europe. 492 European areas at risk encompass diversified (sub)natural ecosystems as well as agro493 ecosystems in which an important research effort should be made to decipher the host 494 plants - insect vectors - bacterium interactions ${ }^{76}$. Only in this way could we develop an 495 496 497

5001 EFSA. Scientific Opinion on the risks to plant health posed by Xylella fastidiosa in 501 the EU territory, with the identification and evaluation of risk reduction options.

502

503

504

505

506

507

508 appropriate and efficient strategy to deal with $X f$ in the coming years.

\section{References}

2 Janse, J. \& Obradovic, A. Xylella fastidiosa: its biology, diagnosis, control and risks. Journal of Plant Pathology, S35-S48 (2010).

3 Tumber, K., Alston, J. \& Fuller, K. Pierce's disease costs California \$104 million per year. California Agriculture 68, 20-29 (2014).

4 Davis, M. J., Purcell, A. H. \& Thomson, S. V. Pierce's disease of grapevines: isolation of the causal bacterium. Science 199, 75-77 (1978).

509

5 Martelli, G., Boscia, D., Porcelli, F. \& Saponari, M. The olive quick decline

510

511

512 syndrome in south-east Italy: a threatening phytosanitary emergency. European Journal of Plant Pathology 144, 235-243 (2016).

6 Hearon, S. S., Sherald, J. L. \& Kostka, S. J. Association of xylem-limited bacteria

513

514

515 with elm, sycamore, and oak leaf scorch. Canadian Journal of Botany 58, 19861993 (1980).

7 Wells, J. M., Raju, B. \& Nyland, G. Isolation, culture and pathogenicity of the

516

517 bacterium causing phony disease of peach. Phytopathology 73, 859-862 (1983).

8 Chang, C. J., Garnier, M., Zreik, L., Rossetti, V. \& Bové, J. M. Culture and serological

518

519

520

521

522

523

524

525

526

527

528

529 detection of the xylem-limited bacterium causing citrus variegated chlorosis and its identification as a strain of Xylella fastidiosa. Current Microbiology 27, 137-142 (1993).

9 Davis, M., Thomson, S. \& Purcell, A. Etiological role of a xylem-limited bacterium causing Pierce's disease in almond leaf scorch. Phytopathology 70, 5 (1980).

10 Almeida, R. P. \& Nunney, L. How do plant diseases caused by Xylella fastidiosa emerge? Plant Disease 99, 1457-1467 (2015).

11 Scally, M., Schuenzel, E. L., Stouthamer, R. \& Nunney, L. Multilocus sequence type system for the plant pathogen Xylella fastidiosa and relative contributions of recombination and point mutation to clonal diversity. Applied and Environmental Microbiology 71, 8491-8499 (2005).

12 Yuan, X. et al. Multilocus sequence typing of Xylella fastidiosa causing Pierce's disease and oleander leaf scorch in the United States. Phytopathology 100, 601611 (2010).

531

532

533

13 Nunney, L., Ortiz, B., Russell, S. A., Sánchez, R. R. \& Stouthamer, R. The complex biogeography of the plant pathogen Xylella fastidiosa: genetic evidence of introductions and subspecific introgression in Central America. PLoS One 9, e112463 (2014).

535

536

537

538

14 Nunney, L., Elfekih, S. \& Stouthamer, R. The importance of multilocus sequence typing: cautionary tales from the bacterium Xylella fastidiosa. Phytopathology 102, 456-460 (2012). 
53915 Schuenzel, E. L., Scally, M., Stouthamer, R. \& Nunney, L. A multigene phylogenetic

540 study of clonal diversity and divergence in North American strains of the plant $541 \quad$ pathogen Xylella fastidiosa. Applied and Environmental Microbiology 71, 3832-

542

543 3839 (2005).

16 Marcelletti, S. \& Scortichini, M. Genome-wide comparison and taxonomic relatedness of multiple Xylella fastidiosa strains reveal the occurrence of three subspecies and a new Xylella species. Archives of Microbiology 198, 803-812 (2016).

545

546

547

17 Bull, C. et al. List of new names of plant pathogenic bacteria (2008-2010). Journal

548

549 of Plant Pathology 94, 21-27 (2012).

550

551

552

553

554

555

556

557

558

559

560

561

562

563

18 Wells, J. M. et al. Xylella fastidiosa gen. nov., sp. nov: gram-negative, xylem-limited, fastidious plant bacteria related to Xanthomonas spp. International Journal of Systematic and Evolutionary Microbiology 37, 136-143 (1987).

19 Nunney, L. et al. Population genomic analysis of a bacterial plant pathogen: novel insight into the origin of Pierce's disease of grapevine in the US. PLoS One 5, e15488 (2010).

20 Nunes, L. R. et al. Microarray analyses of Xylella fastidiosa provide evidence of coordinated transcription control of laterally transferred elements. Genome Research 13, 570-578 (2003).

21 Coletta-Filho, H. D., Francisco, C. S., Lopes, J. R., Muller, C. \& Almeida, R. P. Homologous recombination and Xylella fastidiosa host-pathogen associations in South America. Phytopathology 107, 305-312 (2017).

22 De Lima, J. et al. Coffee leaf scorch bacterium: axenic culture, pathogenicity, and comparison with Xylella fastidiosa of citrus. Plant Disease 82, 94-97 (1998).

23 Nunney, L., Yuan, X., Bromley, R. E. \& Stouthamer, R. Detecting genetic introgression: high levels of intersubspecific recombination found in Xylella fastidiosa in Brazil. Applied and Environmental Microbiology 78, 4702-4714 (2012).

565

566

567

24 Nunney, L., Schuenzel, E. L., Scally, M., Bromley, R. E. \& Stouthamer, R. Large-scale

568

569

570

571

572

573

574

575

576

577

578

579

580

581

582

583

584

585

586 intersubspecific recombination in the plant-pathogenic bacterium Xylella fastidiosa is associated with the host shift to mulberry. Applied and Environmental Microbiology 80, 3025-3033 (2014).

25 Randall, J. J. et al. Genetic analysis of a novel Xylella fastidiosa subspecies found in the southwestern United States. Applied and Environmental Microbiology 75, 5631-5638 (2009).

26 Nunney, L. et al. Recent evolutionary radiation and host plant specialization in the Xylella fastidiosa subspecies native to the United States. Applied and Environmental Microbiology 79, 2189-2200 (2013).

27 Denancé, N. et al. Several subspecies and sequence types are associated with the emergence of Xylella fastidiosa in natural settings in France. Plant Pathology 66, 1054-1064 (2017).

28 EPPO. Normes OEPP EPPO Standards - PM 7/24 (2) Xylella fastidiosa. EPPO bulletin 46, 463-500 (2016).

29 Olmo, D. et al. First detection of Xylella fastidiosa on cherry (Prunus avium) and Polygala myrtifolia plants, in Mallorca Island, Spain. Plant Disease (2017).

30 Amanifar, N., Taghavi, M., Izadpanah, K. \& Babaei, G. Isolation and pathogenicity of Xylella fastidiosa from grapevine and almond in Iran. Phytopathologia Mediterranea 53, 318 (2014). 
58731 Çağlar, B. et al. First report of almond leaf scorch in Turkey. Journal of Plant

588

589

590

591

592

593

594

595

596

597

598

599

600

601

602

603

604

605

606

607

608

609

610

611

612

613

614

615

616

617

618

619

620

621

622

623

624

625

626

627

628

629

630

631

632

633

$634 \quad 48$ Pathology 87 (2005).

32 Su, C. C. et al. Pierce's disease of grapevines in Taiwan: Isolation, cultivation and pathogenicity of Xylella fastidiosa. European Journal of Plant Pathology 161, 389396 (2013).

33 Wallingford, A. K., Myers, A. L. \& Wolf, T. K. Expansion of the range of Pierce's disease in Virginia. Online. Plant Health Progress doi:10.1094/PHP-2007-1004-01BR. (2007).

34 Purcell, A. Environmental therapy for Pierce's disease of grapevines. Plant Disease 64, 388-390 (1980).

35 Feil, H. \& Purcell, A. H. Temperature-dependent growth and survival of Xylella fastidiosa in vitro and in potted grapevines. Plant Disease 85, 1230-1234 (2001).

36 Anas, 0., Harrison, U. J., Brannen, P. M. \& Sutton, T. B. Effect of warming winter temperatures on the severity of Pierce's disease in the Appalachian Mountains and Piedmont of the Southeastern United States. Online. Plant Health Progress doi:10.1094/PHP-2008-0718-01-RS. 1, 450-459 (2008).

37 Lieth, J., Meyer, M., Yeo, K.-H. \& Kirkpatrick, B. Modeling cold curing of Pierce's disease in Vitis vinifera 'Pinot Noir' and 'Cabernet sauvignon' grapevines in California. Phytopathology 101, 1492-1500 (2011).

38 Keller, R. P., Lodge, D. M. \& Finnoff, D. C. Risk assessment for invasive species produces net bioeconomic benefits. Proceedings of the National Academy of Sciences 104, 203-207 (2007).

39 Bosso, L., Febbraro, M., Cristinzio, G., Zoina, A. \& Russo, D. Shedding light on the effects of climate change on the potential distribution of Xylella fastidiosa. Biological Invasions 18, 1759-1768 (2016).

40 Hoddle, M. S. The potential adventive geographic range of glassy-winged sharpshooter, Homalodisca coagulata and the grape pathogen Xylella fastidiosa: implications for California and other grape growing regions of the world. Crop Protection 23, 691-699 (2004).

41 Broennimann, 0. \& Guisan, A. Predicting current and future biological invasions: both native and invaded ranges matter. Biology Letters 4, 585-589 (2008).

42 Kamas, J. et al. Pierce's disease overview and management guide: A resource for grape growers in Texas and other Eastern U.S. growing regions. (Texas A\&M AgriLife Ext., College Station, Texas., 2012).

43 Smith, D., Dominiak-Olson, J. \& Sharber, C. First report of Pierce's disease of grape caused by Xylella fastidiosa in Oklahoma. Plant Disease 93, 762-762 (2009).

44 Fick, S. E. \& Hijmans, R. J. WorldClim 2: new 1 - km spatial resolution climate surfaces for global land areas. International Journal of Climatology 37, 4302-4315 (2017).

45 Watanabe, M. et al. Improved climate simulation by MIROC5: mean states, variability, and climate sensitivity. Journal of Climate 23, 6312-6335 (2010).

46 Flato, G. et al. in Climate Change 2013: The Physical Science Basis. Contribution of Working Group I to the Fifth Assessment Report of the Intergovernmental Panel on Climate Change (eds T.F. Stocker et al.) 741-866 (Cambridge University press, 2013).

47 Van Vuuren, D. P. et al. The representative concentration pathways: an overview. Climatic Change 109, 5-31 (2011).

48 Agresti, A. Categorical Data Analysis. Second edn, (Wiley, 2002). 
63549 R Core Team. R: A language and environment for statistical computing. R

636

637

638

639

640

641

642

643

644

645

646

647

648

649

650

651

652

653

654

655

656

657

658

659

660

661

662

663

664

665

666

667

668

669

670

671

672

673

674

675

676

677

678

679

680

681

Foundation for Statistical Computing, Vienna, Austria. URL https://www.Rproject.org/. (2017).

50 Venables, W. N. \& Ripley, B. D. Modern Applied Statistics with S., (Springer, 2002).

51 Christensen, R. H. B. ordinal - Regression Models for Ordinal Data. R package version 2015.6-28. http://www.cran.r-project.org/package=ordinal/. (2015).

52 Franklin, J. Mapping species distributions: spatial inference and prediction. (Cambridge University Press, 2010).

53 Busby, J. R. BIOCLIM: a bioclimate analysis and prediction system. Plant Prot Q 6, 8-9 (1991).

54 Booth, T. H., Nix, H. A., Busby, J. R. \& Hutchinson, M. F. BIOCLIM: the first species distribution modelling package, its early applications and relevance to most current MAXENT studies. Biodiversity and Conservation 20, 1-9 (2014).

55 Carpenter, G., Gillison, A. \& Winter, J. DOMAIN: a flexible modelling procedure for mapping potential distributions of plants and animals. Biodiversity and Conservation 2, 667-680 (1993).

56 Lobo, J. M. The use of occurrence data to predict the effects of climate change on insects. Current Opinion in Insect Science 17, 62-68 (2016).

57 Phillips, S. J., Anderson, R. P. \& Schapire, R. E. Maximum entropy modeling of species geographic distributions. Ecological modelling 190, 231--259 (2006).

58 Pearson, R. G., Raxworthy, C. J., Nakamura, M. \& Townsend Peterson, A. Predicting species distributions from small numbers of occurrence records: a test case using cryptic geckos in Madagascar. Journal of Biogeography 34, 102-117, doi:10.1111/j.1365-2699.2006.01594.x (2007).

59 Hijmans, R. J., Phillips, S., Leathwick, J. \& Elith, J. dismo: Species Distribution Modeling. R package version 1.1-4. https://CRAN.R-project.org/package=dismo. (2017).

60 Jiménez-Valverde, A. et al. Use of niche models in invasive species risk assessments. Biological Invasions 13, 2785-2797 (2011).

61 Daugherty, M. P., Zeilinger, A. R. \& Almeida, R. P. P. Conflicting Effects of Climate and Vector Behavior on the Spread of a Plant Pathogen. Phytobiomes 1, 46-53 (2017).

62 Araújo, M. B. \& New, M. Ensemble forecasting of species distributions. Trends in Ecology \& Evolution 22, 42-47 (2007).

63 Marmion, M., Parviainen, M., Luoto, M., Heikkinen, R. K. \& Thuiller, W. Evaluation of consensus methods in predictive species distribution modelling. Diversity and Distributions 15, 59-69 (2009).

64 Elith, J., Kearney, M. \& Phillips, S. The art of modelling range-shifting species. Methods in Ecology and Evolution 1, 330-342 (2010).

65 Purcell, A. Cold therapy of Pierce's disease of grapevines [Viral diseases, insect vectors]. Plant Disease Reporter (1977).

66 Wickham, H. ggplot2: Elegant Graphics for Data Analysis. (Springer-Verlag, 2016).

67 Wilke, C. 0. cowplot: Streamlined Plot Theme and Plot Annotations for 'ggplot2'. R package version 0.7.0. https://CRAN.R-project.org/package=cowplot. (2016).

68 Yaseen, T. et al. On-site detection of Xylella fastidiosa in host plants and in "spy insects" using the real-time loop-mediated isothermal amplification method. Phytopathologia Mediterranea 54, 488-496 (2015). 
68269 Cruaud, A. et al. Using insects to detect, monitor and predict the distribution of

683 Xylella fastidiosa: a case study in Corsica. bioRxiv,

684

685 doi:http://dx.doi.org/10.1101/241513 (2018).

686

687

688

70 Cornara, D. et al. Transmission of Xylella fastidiosa by naturally infected Philaenus spumarius (Hemiptera, Aphrophoridae) to different host plants. Journal of Applied Entomology 141, 80-87 (2016).

71 Saponari, M. et al. Infectivity and transmission of Xylella fastidiosa by Philaenus

689

690

691 spumarius (Hemiptera: Aphrophoridae) in Apulia, Italy. Journal of Economic Entomology 107, 1316-1319 (2014).

72 Goodwin, P. \& Zhang, S. Distribution of Xylella fastidiosa in southern Ontario as determined by the polymerase chain reaction. Canadian Journal of Plant Pathology 19, 13-18 (1997).

693

694

695

696

697

73 Milling, A., Meng, F., Denny, T. P. \& Allen, C. Interactions with hosts at cool temperatures, not cold tolerance, explain the unique epidemiology of Ralstonia solanacearum race 3 biovar 2. Phytopathology 99, 1127-1134 (2009).

74 Soberón, J. \& Peterson , A. T. Interpretation of models of fundamental ecological niches and species' distributional areas. Biodiversity Informatics 2, 1-10 (2005).

699 Chauvel, G., Cruaud, A., Legendre, B., Germain, J.-F. \& Rasplus, J.-Y. Rapport de

700 mission d'expertise sur Xylella fastidiosa en Corse., (French Ministry of

701

702

703

704

705

706

707

708

709

710 agriculture and food, Available at: http://agriculture.gouv.fr/sites/minagri/files/20150908 rapport mission corse xylella 31082015b.pdf, 2015).

76 Rasplus, J.-Y. et al. in AFPP - 4e conférence sur l'entretien des jardins végétalisés et infrastructures. (Available from http://arbestense.it/images/Annales JEVI 2016.compressed.pdf).

\section{Acknowledgements}

We thank Pauline De Jerphanion (ANSES) manager of the French national database of Xylella fastidiosa in France as well as the DGAL and the SRAL or feeding that database.

712 We also thank Christian Lannou (INRA, SPE, France) for his interest and support during the course of the project. This work was funded by grants from the SPE department of the INRA (National Agronomic Institute). The funders had no role in study design, data collection and analysis, decision to publish, or preparation of the manuscript. JPR thanks the SNCF (French national railway company) whose recurrent delays allowed him to deeply meditate on the results reported in here.

718

719

720

721

722

723

\section{Figure and table captions}

Figure 1 (A) Pierce's disease (PD) severity map in the United States. Each locality is associated to a PD severity index (low, moderate or high severity) on the basis of the map available in Anas et al ${ }^{36}$ and Kamas et al ${ }^{42}$ ). (B) Occurrence records for the ST6 and ST7 strains in France. Occurrence records for (C) Xylella fastidiosa subsp. pauca and (D) Xylella fastidiosa subsp. multiplex in the Americas.

Figure 2 Predicted potential severity of Pierce's disease in Europe under current and future climate conditions obtained from a cumulative link model (CLM). 1 = low severity, $2=$ moderate severity, $3=$ high severity. Current climate conditions are average 730 temperature for the period 1970-2000 extracted from the Worldclim database ${ }^{44}$. Future 
731 climate estimates were obtained from the MIROC5 global climate model (scenarios 4.5 732 and 8.5). A: Predicted PD severity index for the period 1970-2000. B: Predicted PD 733 severity index in 2050 with the scenarios RCP4.5. C: Predicted PD severity index in 2050 734 with the scenarios RCP8.5. Areas associated to climate conditions that are not met 735 within the range of conditions characterizing the set of reference points in the native 736 range (i.e. MESS index $<0$ see material and methods) are shown in grey.

Figure 3 Predicted potential distribution of $X f$ subsp. pauca in Europe under current and future climate conditions obtained by fitting Bioclim and Domain models. Current climate conditions are average temperatures for the period 1970-2000 extracted from

741 the Worldclim database. Future climate estimates were obtained from the MIROC5 742 global climate model (scenarios 4.5 and 8.5). A: Habitat suitability for the period 1970743 2000. B: Habitat suitability in 2050 for the scenario RCP4.5. C: Habitat suitability in 2050 744 for the scenario RCP8.5. D: Proportion of models predicting presence for the period 1970-2000. E: Proportion of models predicting presence in 2050 for the scenario RCP4.5. F: Proportion of models predicting presence in 2050 for the scenario RCP8.5. 748 models Bioclim and Domain run with 3 different climate datasets (see details in Table 749 1). Maps D, E, F were obtained by averaging the presence/absence maps derived from 750 habitat suitability using the lowest presence threshold. Areas associated to climate 751 conditions that are not met within the range of conditions characterizing the set of 752 reference points in the native range (i.e. MESS index $<0$ see material and methods) are 753 shown in grey.

754

Figure 4 Predicted potential distribution of $X f$ subsp. multiplex in Europe under current and future climate conditions obtained by fitting Bioclim and Domain models. Current climate conditions are average temperatures for the period 1970-2000 extracted from the Worldclim database. Future climate estimates were obtained from the MIROC5 global climate model (scenarios 4.5 and 8.5). A: Habitat suitability for the period 19702000. B: Habitat suitability in 2050 for the scenario RCP4.5. C: Habitat suitability in 2050 for the scenario RCP8.5. D: Proportion of models predicting presence for the period 1970-2000. E: Proportion of models predicting presence in 2050 for the scenario RCP4.5. F: Proportion of models predicting presence in 2050 for the scenario RCP8.5. Maps A, B, C were obtained by averaging (ensemble forecasting) of the outputs of the models Bioclim and Domain run with 3 different climate datasets (see details in Table

766 1). Maps D, E, F were obtained by averaging the presence/absence maps derived from 767 habitat suitability using the lowest presence threshold. Areas associated to climate conditions that are not met within the range of conditions characterizing the set of reference points in the native range (i.e. MESS index $<0$ see material and methods) are shown in grey.

Figure 5 Predicted potential distribution of the French strains ST6 and ST7 ( $X f$ subsp. multiplex) in Europe under current and future climate conditions obtained by fitting Bioclim and Domain models. Current climate conditions are average temperatures for the period 1970-2000 extracted from the Worldclim database. Future climate estimates were obtained from the MIROC5 global climate model (scenarios 4.5 and 8.5). A: Habitat suitability for the period 1970-2000. B: Habitat suitability in 2050 for the scenario RCP4.5. C: Habitat suitability in 2050 for the scenario RCP8.5. D: Proportion of models 
780 predicting presence for the period 1970-2000. E: Proportion of models predicting 781 presence in 2050 for the scenario RCP4.5. F: Proportion of models predicting presence 782 in 2050 for the scenario RCP8.5. Maps A, B, C were obtained by averaging (ensemble 783 forecasting) of the outputs of the models Bioclim and Domain run with 3 different 784 climate datasets (see details in Table 1). Maps D, E, F were obtained by averaging the 785 presence/absence maps derived from habitat suitability using the lowest presence threshold. Areas associated to climate conditions that are not met within the range of conditions characterizing the set of reference points in the native range (i.e. MESS index $<0$ see material and methods) are shown in grey.

789

790

791

792

793

794

795

796

797

798

799

800

801

Table 1. Measures of Bioclim and Domain models transferability calculated for different climate datasets. The area under the curve of the receiver operator curve (AUC) and the sensitivity of each model were calculated on the basis of occurrence records available in the European invaded range for $X f$ subsp. pauca and multiplex. The climate datasets leading to the best performing models were \#1, \#4 and \#7 for subsp. pauca and \#2, \#6 and \# 9 for subsp. multiplex. bio5: maximum temperature of the warmest month; bio6: minimum temperature of the coldest month; bio10: mean temperature of the warmest quarter; bio11: mean temperature of the coldest quarter.

\section{Table 1.}

\begin{tabular}{|c|c|c|c|c|c|c|c|c|c|}
\hline \multirow[t]{3}{*}{ Dataset } & \multirow[t]{3}{*}{ Climate variables } & \multicolumn{4}{|c|}{ Subspecies pauca } & \multicolumn{4}{|c|}{ Subspecies multiplex } \\
\hline & & \multicolumn{2}{|c|}{ BIOCLIM } & \multicolumn{2}{|c|}{ DOMAIN } & \multicolumn{2}{|c|}{ BIOCLIM } & \multicolumn{2}{|c|}{ DOMAIN } \\
\hline & & AUC & Sens. & AUC & Sens. & AUC & Sens. & AUC & Sens. \\
\hline dataset \#1 & bio6 & 0.88 & 1 & 0.9 & 1 & 0.686 & 0.999 & 0.759 & 0.999 \\
\hline dataset \#2 & bio11 & 0.44 & 0.04 & 0.78 & 0.04 & 0.918 & 0.999 & 0.924 & 0.999 \\
\hline dataset \#3 & bio6, bio11 & 0.45 & 0.04 & 0.79 & 0.12 & 0.742 & 0.999 & 0.847 & 0.999 \\
\hline dataset \#4 & bio5, bio6 & 0.96 & 1 & 0.96 & 1 & 0.839 & 0.999 & 0.797 & 0.999 \\
\hline dataset \#5 & bio5, bio11 & 0.5 & 0.04 & 0.92 & 0.16 & 0.838 & 0.999 & 0.801 & 0.999 \\
\hline dataset \#6 & bio10, bio11 & 0.5 & 0.04 & 0.91 & 0.16 & 0.884 & 0.999 & 0.965 & 0.999 \\
\hline dataset \# 7 & bio6, bio1 0 & 0.95 & 1 & 0.95 & 1 & 0.867 & 0.999 & 0.904 & 0.999 \\
\hline dataset \#8 & bio5, bio6, bio 11 & 0.5 & 0.04 & 0.92 & 0.16 & 0.843 & 0.999 & 0.803 & 0.999 \\
\hline dataset \#9 & bio6, bio10, bio11 & 0.5 & 0.04 & 0.91 & 0.16 & 0.871 & 0.999 & 0.933 & 0.999 \\
\hline dataset \#10 & bio5, bio6, bio10, bio11 & 0.5 & 0.04 & 0.92 & 0.16 & 0.853 & 0.999 & 0.819 & 0.999 \\
\hline
\end{tabular}

802

803

804 Supplementary Information accompanies this paper and are available as a pdf file

805 (Godefroid_etal_Xylella_fastidiosa_Europe_suppl_mat.pdf) 
Pierce disease severity index 1970-2000

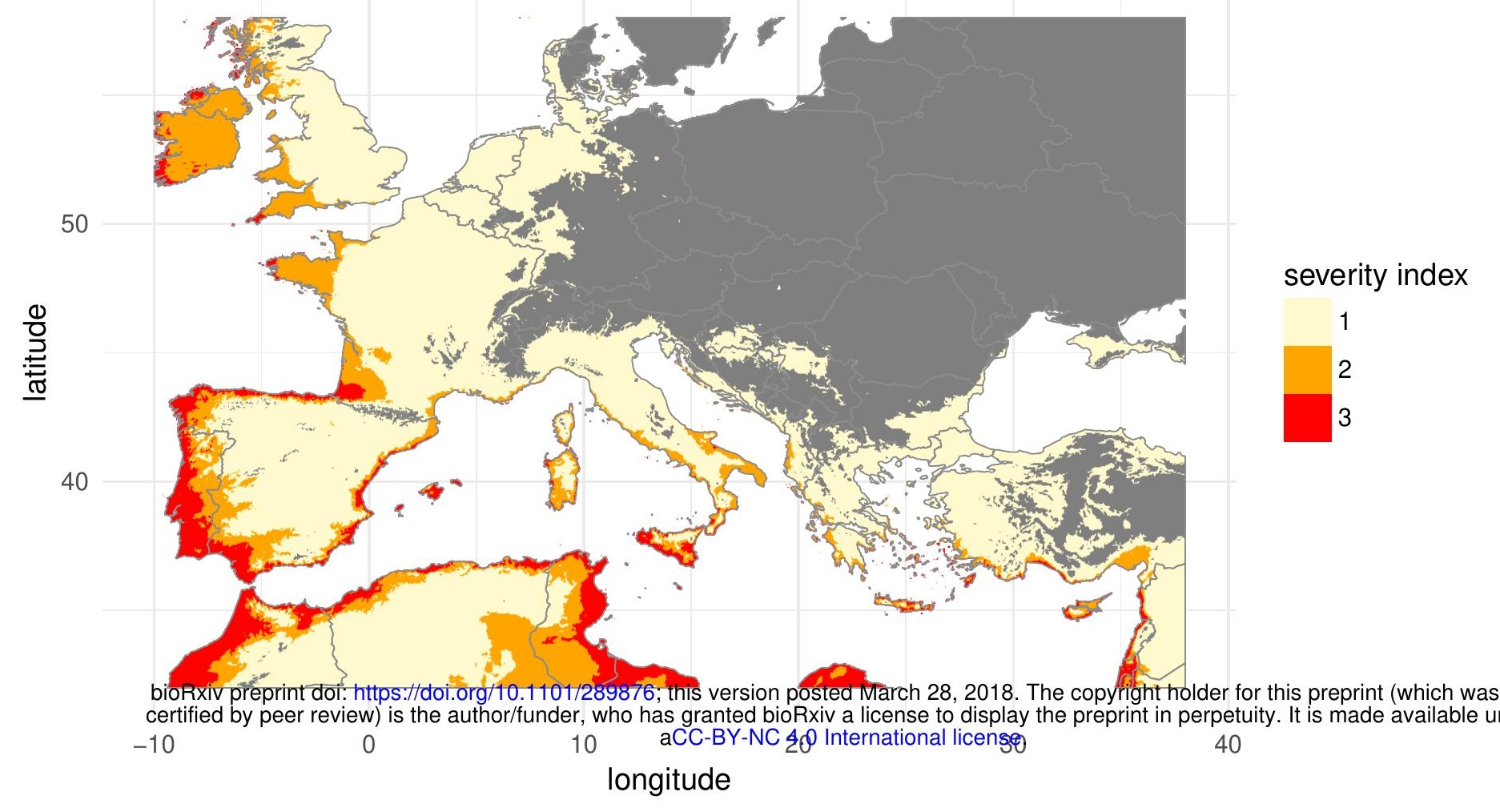

B

Pierce disease severity index 2050 [scenario 4.5]

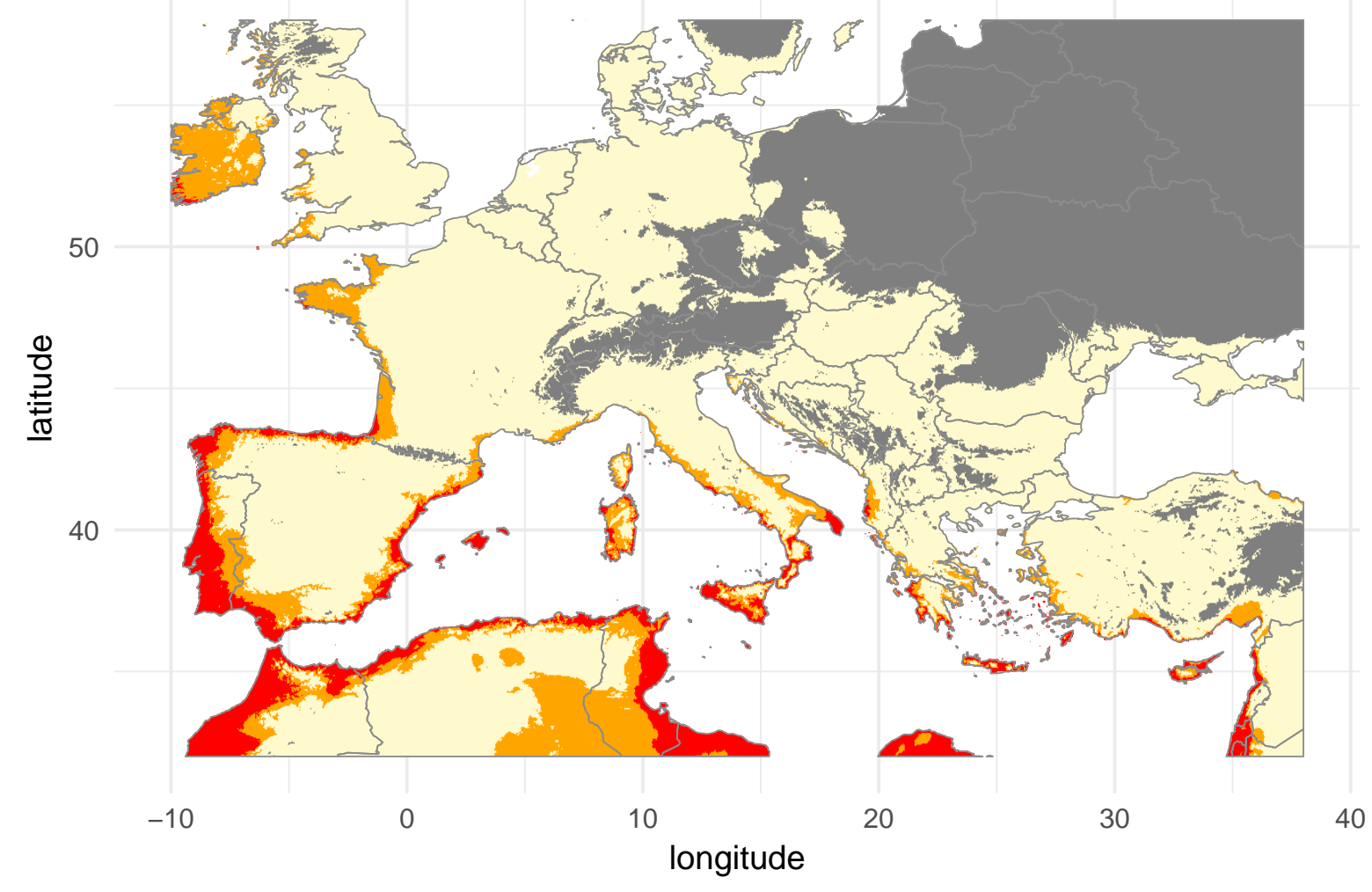

C

Pierce disease severity index 2050 [scenario 8.5]

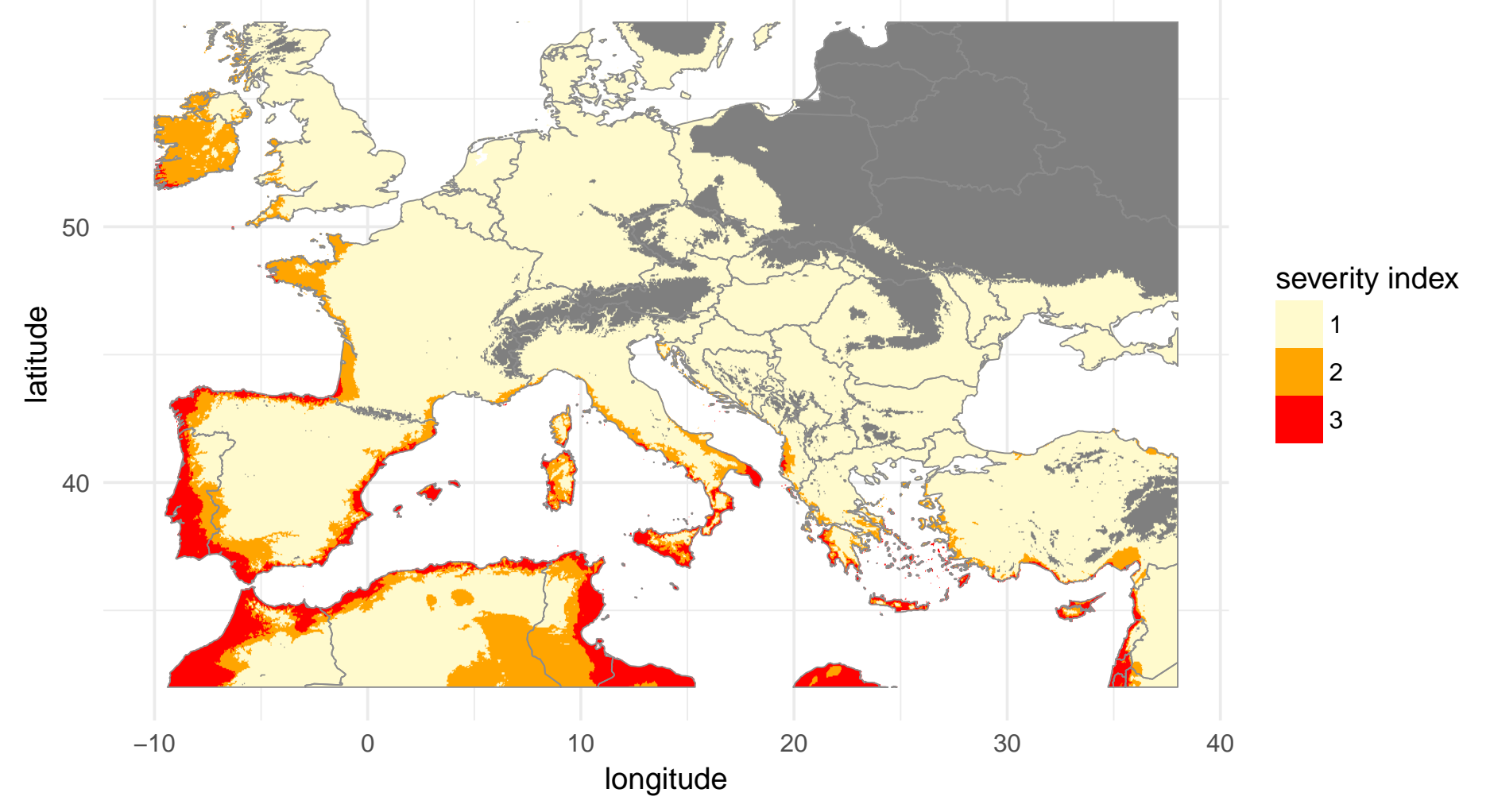


